\title{
Attention control and ability level in a complex cognitive skill: Attention shifting and second-language proficiency
}

\author{
NORMAN SEGALOWITZ and SARAH FRENKIEL-FISHMAN \\ Concordia University, Montreal, Quebec, Canada
}

\begin{abstract}
In this study, we investigated the relationship between attention control and proficiency in a complex cognitive skill. The participants were English-French bilinguals with varying degrees of secondlanguage (French) proficiency. Proficiency was operationalized as efficiency of lexical access in an animacy judgment task, as reflected in the coefficient of variability of response time adjusted for first-language performance on the same task. Attention control was operationalized as the shift cost obtained in a linguistic version of the alternating runs task-switching paradigm. Hierarchical regression revealed that, overall, attention control accounted for $59 \%$ of the variance of proficiency and that secondlanguage attention control alone accounted for $32 \%$ of the unique variance of proficiency, indicating a high degree of skill domain (second language) specificity in the relationship between attention control and proficiency. The results speak to issues regarding the development of expertise, second-language acquisition, and a cognitive linguistic approach to language and attention.
\end{abstract}

One of the most interesting research results of the last half-century regarding skilled performance is that what primarily distinguishes experts from novices is the expert's superior ability to manage attentional resources and to exercise cognitive control. It is not, as might be intuitively assumed, simply the expert's greater memory capacity for domain-relevant information or general ability to process information more quickly. The classic study by A. D. De Groot (1965) illustrated this point well. De Groot compared chess masters with novices in the ability to remember arrangements of pieces on a chessboard and found that after brief inspection, the former were no better in reproducing random arrangements but that they were far superior in reproducing middle game arrangements in which the pieces bore meaningful relationships to one another. The results indicated that experts and novices differed, not in simple memory capacity for unpatterned information, but in the ability to attend to, recognize, and focus on meaningful patterns (for more on the role of memory capacity in expertise, see Ericsson \& Kintsch, 1995; Sohn \& Doane, 2003). Since De Groot's pioneering research, there have been many studies of expertise in chess and in other domains in which the place of cognitive control and attention in expert performance has been examined (e.g., Arthur et al., 1995; Chase \&

This research was supported by a research grant from the Natural Sciences and Engineering Research Council of Canada to the first author. The authors thank Elizabeth Gatbonton and Pavel Trofimovitch for helpful comments on earlier drafts of this article. Correspondence should be addressed to N. Segalowitz, Department of Psychology, Concordia University, Montréal, QC, H4B 1R6 Canada (e-mail: norman. segalowitz@concordia.ca).
Simon, 1973; Feltovich, Spiro, \& Coulson, 1997; Gopher, Weil, \& Seigel, 1989; Reingold, Charness, Schultetus, \& Stampe, 2001; Shebilske, Goettl, \& Regian, 1999).

One domain of expertise in which the role of attention and cognitive control has been little explored is second language (L2) mastery. L2 performance provides interesting possibilities for studying the role of attention in skill acquisition, for several reasons. First, moderate- to high-level L2 skill is probably the norm for adults throughout the world (Dewaele, Housen, \& Wei, 2003) and thus, in terms of universality, surpasses many other domains typically investigated. Second, understanding L2 mastery is especially challenging because of the complex psycholinguistic issues involved (Kroll \& Sunderman, 2003), the possible role played by sensitive periods in development (Birdsong, 1999), the variety of cognitive resources recruited when one learns and uses an L2 (A. M. B. De Groot \& Kroll, 1997), and the complications that arise from the presence of an already developed first language (L1; Odlin, 2003).

Third, the study of L2 expertise also provides the following, possibly unique, opportunity for investigation: Nearly all people with skill in an L2 are already proficient in their L1, making it possible to compare expert and below-expert performance within the same individual. This allows one to ask whether attention control differences associated with variation in bilingual ability reflect individual differences in factors specific to the L2 performance or to more basic, prior existing individual differences that also operate in L1 performance. The present study took advantage of this last possibility in addressing the following question: Do individual differences in pro- 
ficiency in an L2 involve domain-specific (L2-specific) individual differences in attention control? Before describing the research, however, it is necessary to first review some of the different ways attention control may be involved in language proficiency and to consider how proficiency and attention control were operationalized in the study reported here.

\section{Attention, Cognitive Control, and \\ Language Skill}

Attention and cognitive control are multidimensional constructs (Posner, 1995; Posner \& DiGirolamo, 1998) involving a variety of cognitive functions that, in turn, have been linked to various neurobiological substrates. For example, Stuss, Shallice, Alexander, and Picton (1995) attempted to fractionate attention by identifying five main component processes underlying the performance of attention tasks: monitoring, energizing, inhibiting, contention scheduling adjustment, and if-then logic control. They saw these five as occurring in various combinations, as needed, in a variety of types of attentiondemanding situations, including sustaining attention in slow-changing situations in which vigilance is required, concentrating attention during fast paced, highly demanding activities, sharing attention when different cognitive activities must be executed at the same time, suppressing attention when inappropriate action schemata are automatically activated, and shifting attention focus when a complex activity frequently presents changing demands. All of these types of attention-demanding situations (among others) are encountered in the skilled use of language. The underlying cognitive control processes Stuss et al. identified can be clearly distinguished from each other. Nevertheless, when applied to language, they have something in common: They all focus on the way "attention enhances processing of the stimuli that are being attended, and ... inhibit[s] the processing of representations that have been activated but are not relevant to the task that the individual is performing" (Eviatar, 1998, p. 283; see also Fischler, 1998).

There is, however, an additional way to think about the relationship between attention and language, one that more directly addresses what people usually mean by linguistic skill. Language itself can be viewed as an attention-directing system, in a sense expressed by many cognitive linguists (Langacker, 1987; Talmy, 1996, 2000; Tomasello, 1998). The central idea here is that language serves to direct the interlocutor's attention as he or she builds a mental representation of the meaning conveyed in the incoming message. As has been proposed by Langacker and Talmy, this representation or schema construction involves a number of cognitive phenomena, including, among others, foregrounding and backgrounding of information - that is, placing pieces of information in particular relationships to each other (see especially Talmy, 2000, chap.4). Linguistic skill, on this view, involves being able to exercise rapid and flexible control over this attention-directing feature of language.
In order to understand a message, a receiver must create a mental construction corresponding to the sender's intended meaning (as opposed to simply registering the sequence of words spoken). The constructed representation evolves as the message unfolds in time. Particular elements of the message, especially function words and other grammatical devices, serve the purpose of directing the receiver's attention to critical aspects of the representation under construction to ensure that it is modified and updated appropriately. Likewise, to be able to effectively convey a message, one must be able to manipulate the linguistic tools available in the language one is using, in order to shape the receiver's attention as he or she constructs a mental representation of the intended meaning. Skilled language use thus entails (among other things, of course) the ability to handle these attentiondirecting aspects inherent in the language and to do so quickly and accurately.

Slobin (1996) argued that in acquiring their L1, "children are guided by the set of grammatical distinctions in the language to attend to [specific] features of events while speaking. ... Each native language has trained its speakers to pay different kinds of attention to events and experiences when talking about them. This training is carried out in childhood and is exceptionally resistant to restructuring in adult second-language acquisition" (p. 89). In Slobin's (1996) view, adults find "automatizing attention" (p.94, note 11) especially difficult within a second language. Slobin is not explicit about what he means by "automatizing attention," but his view is consistent with the following idea. In a proficient speaker, language processes associated with grammaticized categories are normally automatized, so that they direct attention in ways that are fast, efficient, ballistic (unstoppable), effortless, and largely unconscious. Grammaticized categories refer to categories of words and constructions whose referents "cannot be experienced directly in our perceptual, sensorimotor, and practical dealings with the world" (Slobin, 1996, p.91). Examples include elements of language that refer to aspect (the manner in which an action unfolds, as in She was going to work vs. She has gone to work) or definiteness (signaled in English by $a$ vs. the).

In terms of attention, this means, for example, that when people hear or read in their L1 the sentence The book is under the magazine, they will construct a mental representation that involves (1) eliciting representations corresponding to book and magazine (essentially a lexical access process) and (2) attending to the specific spatial relationship that obtains between book and magazine, signaled by the word order and the preposition under (namely, that the book lies under the magazine and not the other way around) - an attention/cognitive control process. If English is the person's L1, both (1) and (2) will normally be carried out automatically (rapidly, ballistically, and highly efficiently). If, on the other hand, English is the person's L2, then, according to Slobin (1996), the attention-directing aspect of language (part 2 in the present example) will normally pose a challenge. 
In this view, the nouns book and magazine may elicit appropriate representations in a relatively efficient and automatic fashion. In contrast, however, the attentiondirecting functions carried by the grammaticized parts of the sentence will typically not be under as efficient control in the L2 as they are in the L1.

\section{Operationalizing the Attention-Directing Aspect of Language}

The present research tested the hypothesis that L2 proficiency is significantly related to the degree of control the bilingual has over the attention-directing functions of language. Control of attention was operationalized in terms of a person's ability to shift focus of attention from one language-based attention-directing function to another. Moreover, the research also tested the hypothesis that this relationship remains even after taking into account two potential confounds that might compromise a measure of linguistic attention control. One potential confound is individual differences in general ability to read the L2 stimulus words that appear in the attention control task (this would confound attention control with general L2 proficiency). The other potential confound is individual differences in general nonlinguistic forms of attention control that can be expected to operate even in L1 performance. How these two factors were separated from the main variable of interest - attention control in the L2 - will be described below.

In the present research, we investigated languagerelevant attention control by making use, in the context of an attention-shifting paradigm, of two examples of attention-directing functions found in language. The first involved time adverbials, words normally used to direct attention to the temporal location of an event as being closer to or further from some reference point, such as the present moment. The English examples used in this study contrasted now, next, promptly, and shortly with afterward, later, tomorrow, and never. Thus, for example, if someone says "I'll do it now" versus "I'll do it later," a proficient listener will construct a mental representation of the speaker's intention that locates the action part of that representation on something corresponding, at least functionally, to a conceptual time line (see, e.g., Gentner, Imai, \& Boroditsky, 2002). The word now places the action very close to the present moment on this hypothetical time line, and the word later places it relatively further away. Words such as now, later, shortly, afterward, and so forth direct listeners' and readers' attention to the temporal relationship between the topic event and a reference point in time (here, the present moment).

The second example used in this study involved connectives (conjunctions) that normally link ideas by indicating the presence or absence of a causal connection between events named in two parts of a sentence. The English examples used here contrasted because, consequently, due to, and therefore with although, but, despite, and however. If someone says "John did well in his exams because he studied all night," as opposed to "John did well in his exams despite partying all night," a proficient listener will construct representations that foreground the elements in the two components of the sentence differently. Because indicates that the second idea (that John studied all night) is to be foregrounded as the cause of John doing well, whereas despite signals that the second idea (that John partied all night) is not the cause of John's doing well. Words such as because, due to, despite, and so forth direct the listener's or reader's attention to the foregrounding/backgrounding of events in terms of their causal links (here, the presence or absence of a causal connection).

Attention control was assessed as a factor underlying L2 proficiency by looking at the relationship between a bilingual's L2 proficiency and the ability to shift attention between these two different attention-directing functions of words in the L2. It was assumed that better control of the attention-directing aspect of language would be reflected in a superior ability to make such shifts rapidly, because such attention shifts are required during normal language use when speaking, listening, and reading. Individual differences in this attention shift ability were assessed by using a modification of Rogers and Monsell's (1995) alternating runs procedure. The bilingual participants were required to perform attention shift tasks in separate L1 and L2 versions of the procedure. Within a given language block, two attention-focusing tasks based on the above examples - time and causal judgments - alternated in a predictable way. The tasks were presented, as in the alternating runs procedure, with the time (T) and causal (C) tasks alternating in the sequence “... TTCCTTCCTTCC ..." This sequence involved a predictable alternation between repeating $(\mathrm{R}$; performing the same kind of task, $\mathrm{T}$ or $\mathrm{C}$, as on the previous trial) and shifting ( $\mathrm{S}$; performing a different task from the previous trial), yielding the sequence “... SRSRSRSRSRSR ..." As in the Rogers and Monsell version of the alternating runs procedure, the position of a stimulus word on the screen served as a cue as to which task (time or causal judgment) was to be performed on the current trial and also which task would be required in the upcoming trial. Most researchers using the alternating runs procedure have found that people perform faster on repeat trials than on shift trials, even though the participant is fully aware of what the upcoming trial is and has time to prepare for it (Monsell, Sumner, \& Waters, 2003; Rogers \& Monsell, 1995; Wylie \& Allport, 2000). This difference is referred to as the shift cost, and it represents the burden placed on the processing system of having to deal with a change of attention focus.

To control for individual differences in aspects of task performance not related specifically to the L2-such as motor abilities relevant to keypressing, letter-decoding skills, general speed and efficiency of cognitive processing, and so forth - each person's performance in the L1 version of the task served as a baseline measure. Performance in the L1 was partialled out from performance in the L2, and the residual score served as an index of L2 
lexical access ability (see also N. Segalowitz \& Freed, 2004 , for an application of this procedure in a study of the cognitive processes underlying oral fluency).

\section{Operationalizing Language Proficiency}

It was also necessary to operationalize L 2 proficiency. This was done in several ways. First, the participants were screened to ensure that they represented a range of L2 proficiency, that they were proficient enough to perform the experimental tasks in an accurate and rapid manner, and that they were less proficient in the L2 than in the L1. To achieve this, a self-rating scale for bilingualism was used at the time of recruitment, followed by a test in the laboratory of speeded reading of short texts for meaning in both the L1 and the L2.

The self-rating and reading speed measures provided rough indications of a person's overall level of proficiency; however, these were not precise enough to serve as fine indices of individual differences in proficiency. The self-rating scale was inherently subjective, and the reading task involved too many sources of variability to be useful for fine-grained scaling of individual differences. Therefore, once participants were accepted into the study, they were given an additional task. This task was a two-alternative forced choice animacy classification task in separate L1 and L2 blocks. On each trial, a noun appeared on the screen that the participants had to classify, by pressing a reaction time (RT) key, as referring to either something living (e.g., dog, horse) or something nonliving (e.g., table, chair). This task yielded indices of both L1 and L2 ability in lexical access. Again, to control for individual differences in aspects of task performance not related specifically to the L2, performance in the L1 was partialled out from performance in the L2.

To summarize, the study tested the hypothesis that control of attention with grammaticized words is a significant factor underlying L2 proficiency. L2 proficiency was measured using a speeded animacy judgment task. L2-specific proficiency measures were derived by partialling out performance in the $\mathrm{L} 1$ on this task from performance in the L2. L2 attention control was measured using an attention-shifting task involving grammaticized words. Again, L2-specific attention control measures were derived by partialling out L1 performance from L2 performance. The research assessed the extent to which these L2-specific attention control measures and proficiency measures were related.

\section{METHOD}

\section{Participants}

The participants were 16 Concordia University undergraduate students (14 females) $19-44$ years of age ( $M=24$ years). These were selected from a larger pool of approximately 24 volunteer participants who had completed a preliminary screening questionnaire and had indicated that their L1 was English, their L2 was French, and they had no known perceptual or attentional disabilities that could interfere with performance. This pool was narrowed down to
16 participants, all of whom rated themselves at 4 or above on a 5 point scale for English ability in reading, speaking, and writing (where $1=$ no ability and $5=$ native-like ability; $M=4.9$ ), between 2 and 4 on the corresponding French language abilities $(M=3.2)$, and always better in English than in French. In addition, they all rated themselves at 4 or above on a 5-point scale for frequency of use of English in reading, speaking, and writing (where $1=$ never or almost never used and $5=$ main language used; $M=4.9$ ), below 4 on the corresponding usage of French $(M=2.3)$, and always more frequent in English than in French (important because of the bilingual nature of life in Montreal). Potential participants also took a test assessing general speed in reading eight short texts in each language to full comprehension. The 16 participants finally included in the study achieved at least $75 \%$ comprehension in each language on the multiple choice comprehension questions ( chance $=33 \%$ ) and performed more quickly in English (L1; $M=272 \mathrm{msec}$ per word, $S E=14.25)$ than in French $(\mathrm{L} 2 ; M=429 \mathrm{msec}, S E=27.25)$. They were paid C $\$ 16$ for their participation.

\section{Materials}

Lexical access (animacy judgment) task. In this test, 53 animate and 53 inanimate nouns were selected that spanned the range of frequencies from 6 to 274 per million $(M=74.78)$ in English and French, according to the English norms available from Quinlan's (1992) Oxford psycholinguistic data base using the Kučera and Francis (1967) norms, and from 5 to 946 per million $(M=$ 89.89) according to French norms based on Beaudot (1992; median frequency $=42.5$ in each language). The French words were selected with pretesting to ensure that English L1 moderate bilinguals would know their meanings. English words were preceded by the articles the and $a$, and French words were preceded by the articles $l e$ or $l a$ and un or une, counterbalanced across animate and inanimate nouns. These articles were used to highlight the English/French character of the target words and to ensure that English words were read as nouns, as opposed to verbs, since many English nouns can be interpreted as verbs (e.g., hammer).

Attention shift task. In this task, 16 English and 16 French expressions were used. Eight expressions were time-related adverbials typically used to indicate that an event will occur at a time relatively close to the present moment (now, next, promptly, or shortly) or relatively further away from the present moment (afterward, later, tomorrow, or never). The French expressions used were maintenant, tout de suite, promptement, or bientôt, and après, plus tard, demain, or jamais. A further eight expressions were conjunctions that typically link two propositions in a sentence as being causally connected (because, consequently, due to, or therefore) or to signal the absence of a causal connection (although, but, despite, or however). The French expressions used were parce que, à cause de, donc, or car, and mais, malgré, cependant, or néanmoins.

\section{Apparatus}

Materials were displayed on a Macintosh Quadra 630 computer programmed in HyperCard.

\section{Procedure}

The participants were tested individually in each of two sessions, about a day apart. In the first session, the participants performed English and French versions of the language assessment tests and the animacy judgment task. In the second session, the participants performed the attention-shifting task in the two languages.

Lexical access task. Following the reading speed test, the participants were given the animacy judgment task, in which they had to press a key to indicate whether the noun appearing on the screen referred to a living (e.g., a dog) or a nonliving (e.g., the table) object.

Attention-shifting test. In the second session, attention control was assessed using the attention shift test. There was a training phase in which the participants practiced making the two different 
kinds of judgments (time adverbials and causal connectives) without having to shift attention, followed by a test phase in which they made these judgments under conditions requiring attention shifting. For the training phase, the participants were first given instructions on how to classify the time adverbials and the causal connectives, followed by speeded classification trials. These consisted of four blocks. Block 1 trained the participants on one of the tasks in one language, Block 2 trained them on the same task in the other language, and then Blocks 3 and 4 trained them on the second task in the two languages in the same order. Each block consisted of 24 trials, in which the participant saw a single expression in the middle of the screen and had to make the correct judgment by pressing the appropriate key on a numeric keypad as quickly as possible. The participants received audible feedback from the computer when they made errors.

In the test phase, the participants saw a rectangle with four quadrants on the screen. On each trial, one stimulus expression was presented in one of the quadrants. The participants were instructed that stimuli appearing in, say, the top two quadrants would be the timerelated expressions and those in the bottom two quadrants would be the causal connectives. On each subsequent trial, a new stimulus appeared in the quadrant adjacent to the location used on the previous trial, moving clockwise around the screen (say, from top left to top right, bottom right, bottom left, etc.), creating the sequence “... time time cause cause time time...," with repeat and shift trials alternating predictably. There were 10 blocks of trials in each language. Each block consisted of 48 trials; the first 16 were treated as warm-up trials and were not included in the data analysis. The language of the block was alternated so that testing in the L1 and L2 was distributed evenly across the session. There was auditory feedback for errors.

In this test phase, a trial was terminated when the participant responded or when $5 \mathrm{sec}$ had elapsed from stimulus onset. The response-stimulus interval was $150 \mathrm{msec}$. When an error was made, on the next trial, an additional $1,500 \mathrm{msec}$ was added to the response-stimulus interval to allow the participant to recover, and the data from these trials were discarded (Rogers \& Monsell, 1995).

At the end of each training and test block, the participant's percentage of error and mean RT were displayed on the screen as feedback. To increase the participants' interest and motivation, cumulative points were also shown on the screen, one point for each correct response, and one bonus point for each RT that was shorter than the mean on the previous block in that language.

\section{Design}

The basic design of the attention-shifting procedure was a $2 \times 2$ within-subjects factorial. There were two levels of language (L1,
English, or L2, French) and two levels of attention trial type (repeat or shift). The assignment of task quadrants (top two, rightmost two, bottom two, or leftmost two) to the time- or cause-related expressions, the order of languages tested, and the assignment of response keys were counterbalanced across participants. The quadrant on which the first expression appeared at the onset of every block was counterbalanced across participants. The attention trial type (repeat vs. shift) was counterbalanced within each block of trials, alternating regularly. The similarity/difference between the required responses on each successive pair of trials was randomized and counterbalanced over the entire block of trials, within repeat and shift trials, as well as within the two tasks, to avoid positive and negative priming confounds from one trial to the next.

\section{RESULTS AND DISCUSSION}

For all statistical tests reported below, $N=16$, and the alpha level for significance was set at .05. All $t$ tests were two-tailed.

\section{Basic Performance on the Animacy Judgment Task}

Lexical access is obviously a fundamental skill required for nearly all aspects of language performance, and individual differences in lexical access were interpreted here as reflecting, to a large extent, differences in the degree and scope of people's experience with the target language (Kroll \& Sunderman, 2003). For this reason, performance on the L2 animacy judgment task was used as a surrogate measure for general proficiency in the language. As can be seen in Table 1, RTs on this task were significantly shorter in L1 than in L2 $[t(15)=$ $-6.391, S E=30.052, p<.001$ ], as was expected given the participant selection criteria.

In addition to a speed index of proficiency, cognitive efficiency measures were also obtained, on the basis of intraindividual differences in variability of the RTs. N. Segalowitz and S. J. Segalowitz (1993) discussed how differences in intraindividual RT variability, under appropriate circumstances, can be interpreted as indices of automaticity or efficiency of processing (for fuller discussions of these issues, see N. Segalowitz, 2000, 2003;

Table 1

Means and Standard Errors of Reaction Times (RTs, in Milliseconds), Percentage Error Rates, and Intraindividual Coefficients of Variability (CVs) in the Animacy Judgment Task and in the Attention Shifting Task

\begin{tabular}{|c|c|c|c|c|c|c|}
\hline & \multicolumn{2}{|c|}{ RT } & \multicolumn{2}{|c|}{ Error Rate (\%) } & \multicolumn{2}{|c|}{$\mathrm{CV}$} \\
\hline & $M$ & $S E$ & $M$ & $S E$ & $M$ & $S E$ \\
\hline \multicolumn{7}{|c|}{ Animacy judgment } \\
\hline L1 & 748 & 34.28 & 1.4 & 0.6 & .339 & .031 \\
\hline $\mathrm{L} 2$ & 940 & 39.21 & 5.8 & 0.9 & .442 & .021 \\
\hline \multicolumn{7}{|c|}{ Attention shifting } \\
\hline \multicolumn{7}{|c|}{ L1 } \\
\hline Repeat & 639 & 31.21 & 4.3 & 0.5 & .213 & .022 \\
\hline Shift & 745 & 38.59 & 5.5 & 0.9 & .245 & .022 \\
\hline Shift cost & 106 & 19.95 & 1.2 & 0.7 & .032 & .015 \\
\hline \multicolumn{7}{|l|}{ L2 } \\
\hline Repeat & 603 & 23.92 & 3.0 & 0.5 & .163 & .013 \\
\hline Shift & 690 & 31.96 & 5.5 & 0.7 & .195 & .015 \\
\hline Shift cost & 87 & 15.19 & 2.5 & 0.5 & .032 & .010 \\
\hline
\end{tabular}


N. Segalowitz \& Hulstijn, 2005). Complex cognitive tasks, such as lexical access, involve a number of different component processes. For example, the animacy judgment task requires cognitive operations ranging from the relatively automatic recognition of letters making up the stimulus word to less automatic access of the representation of the referent named and, ultimately, to the control process involving judgment of the referent's status as animate or inanimate. One possible explanation for individual differences in speed of lexical access is that faster individuals simply execute all or most of the underlying component operations more rapidly. N. Segalowitz and S. J. Segalowitz referred to this explanation as simple speed-up. Another possible explanation, however, is that faster individuals have reorganized the underlying component operations in some way, such as dropping or reorganizing some of the more controlled component stages in which performance is normally relatively slower and in which the time of execution is more variable. Such reorganization results in faster performance, not because of simple speed-up (performing all operations more quickly) but, rather, because the mix of processing components underlying performance has changed, shifting the balance toward cognitively more efficient components (i.e., toward those that are both faster and more stable in time of execution). N. Segalowitz and S. J. Segalowitz referred to this explanation as restructuring, and they associated restructuring with gains in processing efficiency (increased automaticity) over and above any gains in speed.

N. Segalowitz and S. J. Segalowitz (1993) reasoned that RT variability could be used to index this increased efficiency, potentially allowing one to reject, in a given case, a simple speed-up explanation for faster performance in favor of restructuring. They argued that the coefficient of variability (CV) of the RT - an individual's standard deviation $(S D)$ of RT divided by his or her mean RT - provides an appropriate index (the $S D$ of RT taken alone does not, because the $S D$ can be expected to vary proportionally with RT under conditions of simple speedup). Looked at another way, the CV indexes the variability of performance per millisecond of RT: the lower the variability, the more stable and, hence, more efficient the processing. Although this efficiency index involves the RT in its computation, it is not "driven" by RT in the same direction as the speed index, because RT appears in the denominator in the former and in the numerator in the latter. In this sense, the two measures provide different indices of performance. A lower CV reflects more stable RTs after correcting for the overall speed of responding and, hence, reflects more efficient processing (less "noise" per millisecond of RT). The CV has been used successfully in this manner in several studies (e.g., Kavcic, Krar, \& Doty, 1999; Phillips, Segalowitz, O’Brien, \& Yamasaki, 2004; N. Segalowitz \& S. J. Segalowitz, 1993; N. Segalowitz, Poulsen, \& S. Segalowitz, 1999; N. Segalowitz, Watson, \& S. Segalowitz, 1995; Vigneau, Lavergne, \& Brault, 1998).
As can be seen in Table 1, CVs on correct trials in the animacy judgment task also differed significantly between L1 and L2 $[t(15)=-2.717, S E=0.038, p=$ $.016]$. These results indicated that lexical access, in addition to being faster in L1, was also more efficient in L1 than in L2.

The L1 and L2 RTs were significantly correlated ( $r=$ $.673, p=.004)$, indicating that more than $45 \%$ of the variance of performance in L2 was shared with performance in L1. Mean CVs on the lexical access task, however, did not correlate significantly $(r=-.03$, n.s. $)$, indicating that processing efficiency in one language was not associated with processing efficiency in the other.

As was described earlier, a measure reflecting processing proficiency specific to the L2 was obtained by partialling out the L1 RT and CV from the corresponding L2 RT and CV, respectively. The residuals reflected how much more or less rapid and efficient than expected processing was in the L2 after taking into account processing speed and efficiency in the L1. These languageresidualized measures controlled for factors that might contribute to individual differences in processing speed and efficiency that are not specifically related to L2 performance. The resulting residualized lexical access RT and lexical access CV correlated significantly $(r=.608$, $p=.012$ ), indicating that faster responding in the $\mathrm{L} 2$ was associated with more efficient responding, after controlling for speed and efficiency in the L1. In studies in which lexical decision was used, N. Segalowitz and S. J. Segalowitz (1993) and S. J. Segalowitz, N. S. Segalowitz, and Wood (1998) found that the CV correlated positively with RT, indicating generally that people who responded more quickly tended also to respond more stably (hence, more efficiently). However, in both studies, it was also found that among the slower responding bilinguals, the $\mathrm{CV}$ did not correlate significantly with RT, whereas among the faster responding bilinguals it did. This indicated that individual differences for the slower group of bilinguals could be attributed to differences in speed-up (i.e., some individuals in this group processed more quickly than others, but not necessarily more efficiently), whereas individual differences in the faster group reflected processing efficiency effects (i.e., more than just speed-up effects). For this reason, for the analyses reported below, lexical access $\mathrm{CV}$ was preferred over RT as being the more sensitive measure of individual proficiency differences.

\section{Basic Performance on the Attention-Shifting Task}

Mean RTs for the attention-shifting task on correct trials not following an error trial were analyzed as follows. First, the data were examined to determine whether there were significant shift costs-slower responding on shift trials than on repeat trials. Fifteen of the 16 participants showed a shift cost in the L1, and all 16 showed a shift cost in the L2 (see Table 2 for means and standard errors). The RTs were submitted to a $2 \times 2$ repeated measures analysis of variance, with the variables being language 
(L1 or L2) and attention trial type (repeat or shift). The main effect for attention trial type was significant $\left[F(1,15)=36.54, M S_{\mathrm{e}}=4,101.00, p<.00002\right.$; partial $\left.\eta^{2}=.71\right]$, indicating that the attention shift paradigm was successful in varying the attention control burden between repeat and shift trials. The main effect for language was also significant $\left[F(1,15)=13.68, M S_{\mathrm{e}}=\right.$ $2,385.69, p=.002$; partial $\left.\eta^{2}=.48\right]$, indicating, unexpectedly, that RTs on the attention task were significantly longer in the L1 than in the L2. The language $\times$ attention trial type interaction was not significant $[F(1,15)=1.49$, $p>.2]$, indicating that shift costs did not differ significantly between the two languages.

CVs were similarly analyzed. Fourteen of the 16 participants showed a CV shift cost-less efficient responding on shift trials than on repeat trials - in the L1, and 13 of the 16 participants showed a shift cost in the L2 (see Table 2). The CVs were submitted to a $2 \times 2$ repeated measures analysis of variance, with the variables being language (L1 or L2) and attention trial type (repeat or shift). The main effect for attention trial type was significant $\left[F(1,15)=10.58, M S_{\mathrm{e}}=0.00155, p<.006\right.$; partial $\left.\eta^{2}=.41\right]$, indicating that performance on repeat trials was more efficient (with lower intraindividual variability) than that on shift trials, as might be expected given the intervention of attention control processes on shift trials. The main effect for language was also significant $\left[F(1,15)=11.34, M S_{\mathrm{e}}=0.00362, p=.005\right.$; partial $\left.\eta^{2}=.43\right]$, indicating, again unexpectedly, that mean $\mathrm{CVs}$ on the attention task were significantly higher in the L1 than in the L2. The language $\times$ attention trial type interaction was not significant $[F(1,15)<1$, n.s.].

Correlations between shift and repeat trial RTs were significant and high for the L1 $(r=.857, p<.001)$ and for the L2 $(r=.764, p<.001)$ and for CVs in the two languages $(r=.891$ and .764 , respectively, $p<.001)$. Of central interest in this study was that part of attention control on shift trial performance that was not predictable from repeat trial performance. Consequently, shift costs were recalculated by partialling out repeat trial performance from shift trial performance across the sample of 16 participants, separately for speed and efficiency measures. The residuals obtained in this way reflected, separately for each language, how much faster/slower and more/less efficient participants were than was expected on shift trials, given their performance on repeat trials.

Shift cost RTs, computed as residuals after partialling out repeat RTs from shift RTs, correlated significantly across languages $(r=.655, p=.006)$, indicating that more than $42 \%$ of the variance in the shift cost RT in the $\mathrm{L} 2$ was shared with the L1. The shift cost CV, computed analogously, did not correlate significantly across languages $(r=.233$, n.s. $)$, indicating that attention control efficiency in one language was not significantly associated with the other. Finally, the language residualized attention shift RT and attention shift CV correlated significantly $(r=.704, p=.002)$.

\section{Attention Control and Language Proficiency}

The main goal of this study was to determine whether attention control is an important factor underlying bilingual proficiency. This question was addressed by submitting the data to correlation and regression analyses as follows.

First, a zero-order correlation was computed between the L2 CV indices of cognitive efficiency from the animacy judgment task (after first partialling out the L1 $\mathrm{CVs}$ ) and the L2 attention shift RT indices of speed (obtained by partialling out repeat RTs from shift RTs). This correlation was statistically significant and high $(r=$ $.769, p<.001$ ), indicating that there was a strong relationship between speed of attention control in the L2 condition and bilingual proficiency based on efficiency of lexical access. This attention control measure, of course, potentially included contributions from general attention control and from attention control that might be specific to the $\mathrm{L} 2$.

Next, the data were submitted to hierarchical multiple regression. The residualized bilingual proficiency $\mathrm{CV}$ (L2-specific efficiency) scores were again used as the criterion measure. The L1 and L2 attention shift RT measures were entered separately as predictors. The L1 measure was entered first, to control for general attentionshifting abilities that would be reflected in L1, and the L2 measure was entered second. Table 2 shows the results: $R^{2}$ change for L1 attention speed was significant, accounting for over $27 \%$ of the unique variance in L2 cognitive fluency, and $R^{2}$ change for L2 attention speed accounted for an additional, statistically significant $32 \%$ of the unique variance.

The attention-shifting tasks also yielded CV measures that served as indices of processing efficiency in the sense just described. However, there was no a priori reason, on the basis of either theory or previous results, to prefer CV over RT as a measure of attention control. Follow-up analyses using the L1 and L2 CV-based attention shift measures (reflecting efficiency, rather than speed of attention control) as predictors did not yield significant re-

Table 2

Summary of Hierarchical Multiple Regression Analysis for L1 and L2 Language Attention Shift Measures as Predictors of L2 Proficiency

\begin{tabular}{lccccccc}
\hline \multicolumn{1}{c}{ Variable } & $R$ & $R^{2}$ & $\begin{array}{c}\text { Adjusted } \\
R^{2}\end{array}$ & $\begin{array}{c}R^{2} \\
\text { Change }\end{array}$ & $\begin{array}{c}F \\
\text { Change }\end{array}$ & $d f$ & $p$ \\
\hline L1 attention shift & .522 & .273 & .221 & .273 & 5.246 & 1,14 & .038 \\
L2 attention shift & .771 & .594 & .532 & .322 & 10.311 & 1,13 & .007 \\
\hline
\end{tabular}

Note-Criterion measure of L2 proficiency = residualized lexical access CV. 
sults. Finally, for completeness, analyses with residualized lexical access RTs as the criterion measure were also conducted. These analyses yielded no significant results.

\section{GENERAL CONCLUSIONS}

The main finding in this study was the following: Bilinguals' speed of attention control in the L2 accounted for a significant proportion of the unique variance in their proficiency in that language. This result is especially noteworthy for several reasons.

First, the measure of bilingual proficiency used here was based on a measure of RT variability adjusted for each individual's speed of response after adjusting for each individual's performance on a similar task in the L1. This proficiency measure reflected processing efficiency, and not simply speed of processing as such. Moreover, this measure reflected processing efficiency specific to the $\mathrm{L} 2$ and was not reflective of general processing efficiency.

Second, the measure of attention control had also been adjusted to take into account L1 performance. Hierarchical regression analysis revealed that, when taken together, L1 and L2 attention control accounted for 59\% of the variance in the bilingual proficiency measure. This finding adds support to the general observation made in the introduction regarding the importance of attention in skilled performance. Furthermore, when the contributions of L1 and L2 attention control were assessed separately, both were found to make significant contributions, and in particular, the L2 attention control measure itself accounted for $32 \%$ of the unique variance in language proficiency. This finding indicates that an attention control factor specific to the L2 underlies L2 proficiency (see also N. Segalowitz, O’Brien, \& Poulsen, 1998).

When these results are interpreted, it is also important to remember that the measure of attention control did not reflect lexical access ability, because performance on repeat trials in the attention task was partialled out from performance on shift trials, removing the possibility that the attention shift and the animacy judgment tasks were significantly associated simply because both reflected lexical access ability for reading single words. This result reinforces the conclusion that L2 attention control plays an important role in L2 proficiency, independently of a person's skill in accessing L2 word meanings. More generally, the finding strengthens the view that in complex cognitive skills, domain-relevant control of attention is important for overall skill proficiency in a way that complements the ability to access domain-relevant information.

Other aspects of the data merit comment. No significant effects were obtained when the proficiency criterion measure was lexical access RT, rather than CV. This is interesting because in most studies in the literature, measures based on RT and/or accuracy have been used. Of course, differences in RT can, in some circumstances, re- flect differences in simple speed of processing, and not differences in the underlying manner of processing. However, according to the cognitive efficiency interpretation of the CV given earlier, when individual differences in $\mathrm{RT}$ correlate with $\mathrm{CV}$, as they did here, one can reject the hypothesis that only simple differences in speed of operation of underlying mechanisms account for the observed individual differences. This points to the alternative explanation that individual differences were due to differences in efficiency of underlying processes, a factor that is better reflected in the CV than in the RT. That is, in the present study, faster individuals were processing more efficiently (more stably), not simply more quickly. This is what one would expect in the case of a complex skill such as L2 mastery; more skilled bilinguals process differently, as compared with less skilled bilinguals.

It was noted that, somewhat unexpectedly, responses were slower in the L1 in the attention-shifting task than in the L2 and that shift cost differences did not favor the L1 over the L2. It is not entirely clear why this result was found, although N. Segalowitz and de Almeida (2002) discussed a similar case of "worse" performance in the stronger L1. They attributed it to interesting phenomena that can arise in experiments in which repeated presentations of a small set of stimuli are used. They suggested that in some tasks, the reappearance of the same small set of stimuli across many trials leads to increased perceptual fluency for those particular words, removing any L1 perceptual advantage in reading. They also suggested that L1 stimuli generally have richer within-language associations than do the L 2 stimuli, leading to interference and, hence, to slower responding in the L1 than in the L2. These factors could have reduced L1-L2 differences in the attention task, but not in the animacy judgment task, where each stimulus was encountered only once. Such reductions in L1-L2 differences in the attention task, of course, need not necessarily affect the correlation between L2 attention control and L2 lexical access skill, and here they clearly did not.

The finding that the attention control measures correlated significantly with the bilingual proficiency measures supports Slobin's (1996) idea that a specifically linguistic form of attention underlies skilled L2 ability. Of course, it would be premature to draw conclusions from the present study about the causal connection between bilingual proficiency and attention control. One plausible interpretation of the results is that as a bilingual gains L2-relevant attention control skills, overall ability in the domain improves as a result (e.g., greater attention control might lead to improved vocabulary learning). It could also be true, however, that as a bilingual gains in efficiency (automaticity) of lexical access, the proficiency measure used here, their overall ability to control attention improves (e.g., greater efficiency in word processing might lead to better allocation of resources in developing attention control skills). The developmental relationship between these variables would be interesting to explore in future research; the present 
study demonstrated how one might operationalize these constructs for just such a study.

Slobin (1996) suggested that it was automatic control of attention that was especially important for bilingual proficiency. The results of this study offer only suggestive evidence on this point. In this study, it was the speed measure of attention shifting that predicted bilingual ability, not the efficiency of attention shifting. Insofar as the CV measure of processing efficiency lends itself to an automaticity interpretation (N. Segalowitz, 2003), this result does not support Slobin's idea. On the other hand, attention shift CV did correlate significantly with the attention shift RT, suggesting that bilinguals with greater speed of attention control were also more efficient (more automatized) in attention control, over and above what could be attributed to simple speed-up effects. This result is consistent with Slobin's suggestion. It would, therefore, be interesting to further explore the relationship between automaticity and attention control in the context of L2 acquisition.

In summary, the results of this study demonstrated that attention control does play a significant role in skilled L2 ability and, in particular, in ways that flow from a cognitive linguistic view of the relationship between language and attention. The main finding was that attention control, as reflected in attention shift costs, was strongly associated with efficiency, as opposed to speed, of lexical access. The participants were bilingual to varying degrees, and so it was possible for each person to serve as his or her own control and, thereby, provide baseline performance measures in the L1. This feature of the study made it possible to uncover a considerable degree of domain specificity (to the L2) in the relationship between attention control and proficiency level. The pattern of results was consistent with the viewpoint emerging in the general skill development literature that executive processes and attention control play an important role in the acquisition of expertise. The outcome of this research suggests that the study of skill development in an L2 can contribute much to a general understanding of expertise.

\section{REFERENCES}

Arthur, W., Jr., Strong, M. H., Jordan, J., Williamson, J., SheBILSKE, W., \& REgIAN, W. (1995). Visual attention: Individual differences in training and predicting complex task performance. Acta Psychologica, 88, 3-23.

BEAUDOT, J. (1992). Fréquences d'utilisation des mots en français écrit contemporain. Montréal: Presses de l'Université de Montréal.

BIRDSONG, D. (Ed.) (1999). Second language acquisition and the critical period hypothesis. Mahwah, NJ: Erlbaum.

Chase, W. G., \& Simon, H. A. (1973). The mind's eye in chess. In W. G. Chase (Ed.), Visual information processing (pp. 215-281). New York: Academic Press.

De Groot, A. D. (1965). Thought and choice in chess (2nd ed.). The Hague: Mouton.

De Groot, A. M. B., \& Kroll, J. F. (Eds.) (1997). Tutorials in bilingualism: Psycholinguistic perspectives. Hillsdale, NJ: Erlbaum.

Dewaele, J.-M., Housen, A., \& WeI, L. (2003). Introduction and overview. In J.-M. Dewaele, A. Housen, \& L. Wei (Eds.), Bilingualism: Beyond basic principles (pp. 1-9). Clevedon, U.K.: Multilingual Matters.
ERICSSON, K. A., \& KinTSCH, W. (1995). Long-term working memory. Psychological Review, 102, 211-245.

EVIATAR, Z. (1998). Attention as a psychological entity and its effects on language and communication. In B. Stemmer \& H. A. Whitaker (Eds.), Handbook of neurolinguistics (pp. 275-287). New York: Academic Press.

Feltovich, P. J., Spiro, R. J., \& Coulson, R. L. (1997). Issues of expert flexibility in contexts characterized by complexity and change. In P. J. Feltovich, K. M. Ford, \& R. R. Hoffman (Eds.), Expertise in context (pp. 125-146). Cambridge, MA: MIT Press.

Fischler, I. (1998). Attention and language. In R. Parasuraman (Ed.), The attentive brain (pp. 381-399). Cambridge, MA: MIT Press.

Gentner, D., Imai, M., \& Boroditsky, L. (2002). As time goes by: Evidence for two systems in processing space $\rightarrow$ time metaphors. Language \& Cognitive Processes, 17, 537-565.

Gopher, D., WeIL, M., \& Siegel, D. (1989). Practice under changing priorities: An approach to training of complex skills. Acta Psychologica, 71, 147-177.

KaVCIC, V., KRAR, F. J., \& Doty, R. W. (1999). Temporal cost of switching between kinds of visual stimuli in a memory task. Cognitive Brain Research, 9, 199-203.

KROLL, J. F., \& SUNDERMAN, G. (2003). Cognitive processes in second language learners and bilinguals: The development of lexical and conceptual representations. In C. J. Doughty \& M. H. Long (Eds.), The handbook of second language acquisition (pp. 104-129). Oxford: Blackwell.

KuČERA, H., \& FrANCIS, W. N. (1967). Computational analysis of presentday American English. Providence, RI: Brown University Press.

LANGACKer, R. W. (1987). Foundations of cognitive grammar, Vol. I: Theoretical prerequisites. Stanford, CA: Stanford University Press.

Monsell, S., Sumner, P., \& Waters, H. (2003). Task-set reconfiguration with predictable and unpredictable task switches. Memory \& Cognition, 31, 327-342.

ODLIN, T. (2003). Cross-linguistic influence. In C. Doughty \& M. Long (Eds.), The handbook of second language acquisition (pp. 436-486). Oxford: Blackwell.

Phillips, N. A., Segalowitz, N., O'Brien, I., \& Yamasaki, N. (2004). Semantic priming in a first and second language: Evidence from reaction time variability and event-related brain potentials. Journal of Neurolinguistics, 17, 237-262.

PoSNER, M. (1995). Attention in cognitive neuroscience: An overview. In M. S. Gazzaniga (Ed.), The cognitive neurosciences (pp. 615-624). Cambridge, MA: MIT Press.

Posner, M. I., \& DiGirolamo, G. J. (1998). Executive attention: Conflict, target detection, and cognitive control. In R. Parasuraman (Ed.), The attentive brain (pp.401-423). Cambridge, MA: MIT Press.

Quinlan, P. T. (1992). Oxford psycholinguistic database. Oxford: Oxford University Press.

Reingold, E. M., Charness, N., Schultetus, R. S., \& Stampe, D. M. (2001). Perceptual automaticity in expert chess players: Parallel encoding of chess relations. Psychonomic Bulletin \& Review, 8, 504510.

Rogers, R. D., \& Monsell, S. (1995). Costs of a predictable switch between simple cognitive tasks. Journal of Experimental Psychology: General, 124, 207-231.

SEGALOWITZ, N. [S.] (2000). Automaticity and attentional skill in fluent performance. In H. Riggenbach (Ed.), Perspectives on fluency (pp. 200-219). Ann Arbor: University of Michigan Press.

SEgalowitz, N. [S.] (2003). Automaticity and second language learning. In C. Doughty \& M. Long (Eds.), The handbook of second language acquisition (pp. 382-408). Oxford: Blackwell.

Segalowitz, N. [S.], \& De Almeida, R. G. (2002). Conceptual representation of verbs in bilinguals: Semantic field effects and a second language performance paradox. Brain \& Language, 80, 517-531.

Segalowitz, N. [S.], \& Freed, B. F. (2004). Context, contact, and cognition in oral fluency acquisition: Learning Spanish in at home and study abroad contexts. Studies in Second Language Acquisition, 26, 173-199.

Segalowitz, N. [S.], \& Hulstijn, J. (2005). Automaticity in bilingualism and second language learning. In J. F. Kroll \& A. M. B. De Groot (Eds.), Handbook of bilingualism: Psycholinguistic approaches (pp.371-388). Oxford: Oxford University Press. 
Segalowitz, N. [S.], O’Brien, I., \& Poulsen, C. (1998). Evidence for a domain-specific component of attentional control in skilled performance. Brain \& Cognition, 37, 129-132.

Segalowitz, N. [S.], Poulsen, C., \& Segalowitz, S. [J.] (1999). RT coefficient of variation is differentially sensitive to executive control involvement in an attention-switching task. Brain \& Cognition, 40, 255-257.

Segalowitz, N. S., \& Segalowitz, S. J. (1993). Skilled performance, practice, and the differentiation of speed-up from automatization effects: Evidence from second language word recognition. Applied Psycholinguistics, 14, 369-385.

SeGalowitz, N. [S.], Watson, V., \& Segalowitz, S. [J.] (1995). Vocabulary skill: Single-case assessment of automaticity of word recognition in a timed lexical decision task. Second Language Research, 11, 121-136.

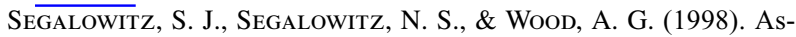
sessing the development of automaticity in second language word recognition. Applied Psycholinguistics, 19, 53-67.

ShebiLske, W., GoetTL, B., \& Regian, J. W. (1999). Executive control of automatic processes as complex skills develop in laboratory and applied settings. In D. Gopher \& A. Koriat (Eds.), Attention and performance XVII: Cognitive regulation of performance. Interaction of theory and application (pp. 401-432). Cambridge, MA: MIT Press.

SLOBIN, D. (1996). From "thought and language" to "thinking for speaking.” In J. J. Gumperz \& S. C. Levinson (Eds.), Rethinking linguistic relativity (pp. 70-96). Cambridge: Cambridge University Press.
Sohn, Y. W., \& Donne, S. M. (2003). Roles of working memory capacity and long-term working memory skill in complex task performance. Memory \& Cognition, 31, 458-466.

Stuss, D. T., Shallice, T., AleXander, M. P., \& Picton, T. W. (1995). A multidisciplinary approach to anterior attentional functions. In J. Grafman, K. J. Holyoak, \& F. Boller (Eds.), Structure and functions of the human prefrontal cortex (Annals of the New York Academy of Sciences, Vol. 769, pp. 191-211). New York: New York Academy of Sciences.

TALMY, L. (1996). The windowing of attention. In M. Shibatani \& S. A. Thompson (Eds.), Grammatical constructions (pp. 235-287). Oxford: Oxford University Press.

Talmy, L. (2000). Toward a cognitive semantics (Vols. 1 and 2). Cambridge, MA: MIT Press.

Tomasello, M. (1998). Introduction: A cognitive-functional perspective on language structure. In M. Tomasello (Ed.), The new psychology of language (pp. vii-xxiii). Mahwah, NJ: Erlbaum.

Vigneau, F., Lavergne, C., \& Brault, M. (1998). Automaticité du traitement de l'information et évaluation du retard mental [Automaticity of information processing and intellectual assessment of the mentally retarded]. Canadian Journal of Behavioural Science, 30, 99-107.

Wylie, G., \& AllPORT, A. (2000). Task switching and the measurement of "switch costs." Psychological Research, 63, 212-233.

(Manuscript received October 21, 2003; revision accepted for publication August 15, 2004.) 